\title{
The stress hormone norepinephrine increases migration of prostate cancer cells in vitro and in vivo
}

\author{
ANTONIO BARBIERI $^{1}$, SABRINA BIMONTE ${ }^{1}$, GIUSEPPE PALMA ${ }^{1}$, ANTONIO LUCIANO ${ }^{1}$, \\ DOMENICA REA $^{1}$, ALDO GIUDICE ${ }^{1}$, GIOSUÈ SCOGNAMIGLIO ${ }^{2}$, ELVIRA LA MANTIA ${ }^{2}$, \\ RENATO FRANCO ${ }^{2}$, SISTO PERDONA ${ }^{3}$, OTTAVIO DE COBELLI ${ }^{4}$, MATTEO FERRO $^{4}$, \\ SILVIA ZAPPAVIGNA $^{5}$, PAOLA STIUSO ${ }^{5}$, MICHELE CARAGLIA $^{5}$ and CLAUDIO ARRA ${ }^{1}$ \\ ${ }^{1}$ Animal Facility Unit, ${ }^{2}$ Pathology Unit, ${ }^{3}$ Urogynecological Unit, National Institute of Tumours of Naples 'Pascale', \\ Naples; ${ }^{4}$ Urology Unit, European Institute of Oncology, Milan; ${ }^{5}$ Department of Biochemistry, \\ Biophysics and General Pathology, Second University of Naples, Naples, Italy
}

Received January 20, 2015; Accepted February 23, 2015

DOI: 10.3892/ijo.2015.3038

\begin{abstract}
The metastatic process is the most serious cause of cancer death. Norepinephrine, secreted in chronic stress conditions, stimulates the motility of breast and colon cells through $\beta$-adrenergic receptor. On these bases, we examined its possible role in metastasis formation and development in vitro and in vivo. Treatments with norepinephrine ( $\beta 2$-adrenoreceptor agonist) in mice xenografted with human DU145 prostate cancer cells increased the metastatic potential of these cells. Specifically, we showed that treatment of mice with norepinephrine induced a significant increase of the migratory activity of cancer cells in a concentration-dependent manner and that this process was blocked by propanolol ( $\beta$-adrenergic antagonist). Mice treated with norepinephrine, displayed an increased number of metastatic foci of DU145 cells in inguinal lymph nodes and also showed an increased expression of MMP2 and MMP9 in tumor samples compared to controls. Moreover, we demonstrated that propanolol induced in norepinephrine treated DU145 cells a E-cadherin finger-like membrane protrusions driven by vimentin remodeling. Altogether these data suggest that $\beta 2$-AR plays an
\end{abstract}

Correspondence to: Professor Michele Caraglia, Department of Biochemistry, Biophysics and General Pathology, Second University of Naples, Via L. De Crecchio 7, Naples I-80138, Italy

E-mail:michele.caraglia@unina2.it; michele.caraglia@alice.it

Abbreviations: CK, cytokeratin; E, epinephrine; EMT, epithelialmesenchymal transition; IHC, immunohistochemistry; Ig, immunoglobulin; NE, norepinephrine; SDS-PAGE, sodium dodecyl sulfate polyacrylamide gel electrophoresis; $\beta 2$-AR, $\beta 2$-adrenoreceptor

Key words: cell invasion, cell migration, epithelial-mesenchymal transition, metastases, norepinephrine, prostate cancer, stress, $\beta$-adrenergic receptors important role in prostate cancer metastasis formation and that the treatment with antagonist propanolol, could represents an interesting tool to control this process in cells overexpressing $\beta 2 \mathrm{AR}$.

\section{Introduction}

The fight or flight response triggered by stress is elicited by the production of mediators, such as the catecholamines, norepinephrine (NE) and epinephrine (E), from the sympathetic nervous system and the adrenal medulla. The hypothalamic-pituitary-adrenal response includes the release of corticotrophin-releasing hormone from the hypothalamus and the secretion of adrenocorticotrophic hormone from the anterior pituitary. This process results in a downstream release of glucocorticoids, such as cortisol, from the adrenal cortex. The tumor is not independent from its microenvironment $(1,2)$; in fact, it interacts with its adjacent cells and also with neuroendocrine system. Tumor cells express different neurotransmitter receptors and react with different neurotransmitters released by the autonomic nervous system from the brain, peripheral plexuses, ganglia and adrenal medulla $(1,2)$. Therefore, it is increasingly clear that malignant tumors are under the regulatory control of the nervous system, and that these signals may represent a metastatic drive to tumor cells. This process is called neoneurogenesis and, as angiogenesis forms new vessel in the tumors, it occurs when produced neurotrophins stimulate adjacent nerve cells to develop nerve endings into the tumor. This innervation could stimulate the development of metastases, since tumor cells respond to neurotransmitters with increased migratory activity (e.g., norepinephrine). Actually, many biological cancer findings are focused on the regulation of migration of tumor cells that is a prerequisite for cancer invasion and metastasis. For example, it has been shown that chemo-kinesis induces the migration of tumor cells $(1,2)$, and directs the tumor cells to specific organs (3). Norepinephrine is a neurotransmitter released in stress reactions. The long-lasting elevation of catecholamines attributable to chronic stress, is known to be a risk factor for heart disease 
as well as for cancer. Previous studies provided molecular evidence for a functional link between psychoneurological events, through the increasing release of the neurotransmitter norepinephrine in vivo, and their promigratory influence in tumor cells in vitro. In previous studies, some authors examined the expression of $\beta 2$-adrenoreceptor ( $\beta 2$-AR) in breast, colon and prostatic cancer, and raised the possibility that $\beta 2$-AR could be involved in metastasis to the location of these cancers (4-8). Epithelial-mesenchymal transition (EMT) has a key role in the progression of cancer to an invasive phenotype. The differential remodeling of E-cadherin and vimentin has been characterized in cells that have undergone EMT. The loss of E-cadherin occurs in most epithelial cancers, and can be correlated to higher mobility and invasiveness of tumor cells $(9,10)$. On the other hand, the increased vimentin expression is usually associated with increased in vitro motility of cancer cell lines $(9,10)$.

In the present study, we found that treatment with norepinephrine induces an increased in vitro and in vivo migration of DU145 human hormone-independent prostate cancer cell line. Moreover, in norepinephrine treated mice the increased expression of MMP2 and MMP9 in tumor tissues is paralleled by the presence of metastasis in lymph nodes proximal to the tumor. These effects are antagonized by $\beta 2 \mathrm{AR}$ antagonist propranolol. Collectively, the data show that norepinephrine initiates and drives migration providing a rationale for both the development and localization of metastases and that $\beta$-blockers such as propranolol could be used for chemoprevention of metastasis development.

\section{Materials and methods}

Cells. Human prostate cancer cell line hormone-independent DU145, was purchased from American Type Culture Collection (ATCC, Manassas, VA, USA) and grown in Dulbecco's Modified Eagle's medium (DMEM) supplemented with glutamine, essential and non-essential amino acids, vitamins, antibiotics, and $10 \%$ heat-inactivated fetal bovine serum (Gibco/Invitrogen, Grand Island, NY, USA). The cells were maintained at $37^{\circ} \mathrm{C}$ in a humidified atmosphere of $5 \% \mathrm{CO}_{2}$. All experiments were performed with cultures grown for no longer than 6 weeks after recovery from frozen stocks.

Animals. Thirty-eight-week-old male Foxn ${ }^{\text {nu/nu }}$ mice were purchased by Harlan, San Pietro al Natisone (Italy). Mice were housed 5 per cage and maintained on a 12-h light:12-h dark cycle (lights on at 7.00 a.m.) in a temperature-controlled room $\left(22 \pm 2^{\circ} \mathrm{C}\right)$ and with food and water ad libitum. The experimental protocols were in compliance with the European Community Council directive (86/609/EEC). After 1-week of acclimation to the housing conditions, mice were injected subcutaneously (s.c.) with a suspension of DU145 cells $\left(1 \times 10^{6}\right.$ cells/mouse in the right hind limb).

After 1 week, mice were randomized for tumor volume and weight according to Fisher's exact test. Tumor growth was measured every 2-3 days with a digital caliper $2 \mathrm{BIOL}$ (Besozzo, Italy) and expressed as volume, according to the formula: $\mathrm{V}=(\mathrm{a} \times \mathrm{b} 2) / 2(\mathrm{a}=$ the largest superficial diameter and $\mathrm{b}=$ the smallest superficial diameter). Animals, were sacri- ficed with cervical dislocation when they reached the cut-off of $1500 \mathrm{~mm}^{3}$ or when presenting signs of pain.

Drug administration. When the tumor mass was palpable and measurable, mice were treated with S-propranolol hydrochloride, a non-selective $\beta$-adrenoreceptor antagonist (Sigma-Aldrich, St. Louis, MO, USA) (2 mg/kg/day), and with $28 \mu \mathrm{M}$ of norepinephrine tartrate (Sigma-Aldrich) via intraperitoneal injection, or either combination every day until they reached the cut-off.

Wound healing assay or proliferation assay. DU145 cells were seeded at the density of $40 \times 10^{3}$ cells per well into a 24-multiwell plate, and cultured in their respective culture medium supplemented with $1 \%$ FBS. At the time of confluence, the cells were incubated in the absence or presence of norepinephrine and propranolol and their combination at same concentration $(10 \mu \mathrm{M})$ for 24 and $48 \mathrm{~h}$. Then, a slit was made horizontally with a white tip at the center of each confluent well, the medium was changed after gentle rinse and cells were cultured for $24 \mathrm{~h}$ with or without norepinephrine and propranolol. Cell invasion on the slit of the confluent well, was assessed at time 0,24 and $48 \mathrm{~h}$ in each condition, by light microscopy.

Invasion test. In vitro cell migration was assayed in 24-well cell culture plates using inserts with $8-\mu \mathrm{m}$ pore membranes (Costar, San Diego, CA, USA) according to the method described by Katayama et al (11). In brief, membrane was precoated with $20 \mu \mathrm{l}$ per insert of Matrigel (BD Pharmingen, Bedford, MA, USA) diluted 1:1 by RPMI-1640. DU145 cell line $\left(1 \times 10^{5}\right.$ per $\left.\mathrm{ml}\right)$ were suspended in $500 \mu \mathrm{l}$ migration buffer (DMEM/0.5\% bovine serum albumin) per well and loaded into the upper compartment of the chamber. The lower compartment of the chamber was loaded with $10-400 \mathrm{ng} / \mathrm{ml}$ norepinephrine (Sigma, St. Louis, MO, USA) in $500 \mu \mathrm{l}$ migration buffer. After incubation at $37^{\circ} \mathrm{C}$ for $24 \mathrm{~h}$, the cells on the lower surface of membrane were fixed in $70 \%$ ethanol, stained with hematoxylin, and counted under a microscope (Olympus, Tokyo, Japan). Each value was expressed as a mean number of five different fields. Three experiments were performed independently and the results were compared.

MTT. Cell viability was evaluated using 3-(4, 5-dimethyl (thiazol-2-yl)-2, 5-diphenyltetrazolium bromide) (MTT), the reagent that measures the metabolic activity of cells. The stock solution of MTT $(5 \mathrm{mg} / \mathrm{ml})$ was prepared in phosphatebuffered saline (PBS) and stored in the dark at $4^{\circ} \mathrm{C}$. A $100-\mu 1$ aliquot of a dilution prepared in culture medium $(1 \mathrm{mg} / \mathrm{ml}$ final) was filtered $(0.22 \mu \mathrm{m})$ and added to the cells growing with/without CBGM. After $3 \mathrm{~h}$ of incubation the supernatant was removed. Formazan crystals in viable cells were dissolved in ethanol $(96 \% \mathrm{v} / \mathrm{v})$ and absorbance was measured by the Multiskan ${ }^{\circledR}$ FC microplate photometer (Thermo Scientific, USA) at $540 \mathrm{~nm}$. After the treatment described above, MTT (Sigma) was added to a final concentration of $0.5 \mathrm{mg} / \mathrm{ml}$ and incubated for $4 \mathrm{~h}$ at $37{ }^{\circ} \mathrm{C}$. The culture medium was then removed, and the remaining blue precipitate was solubilized in DMSO followed by an absorbance reading at $570 \mathrm{~nm}$ in a plate reader using $630 \mathrm{~nm}$ as a reference (Spectra Max 340; 

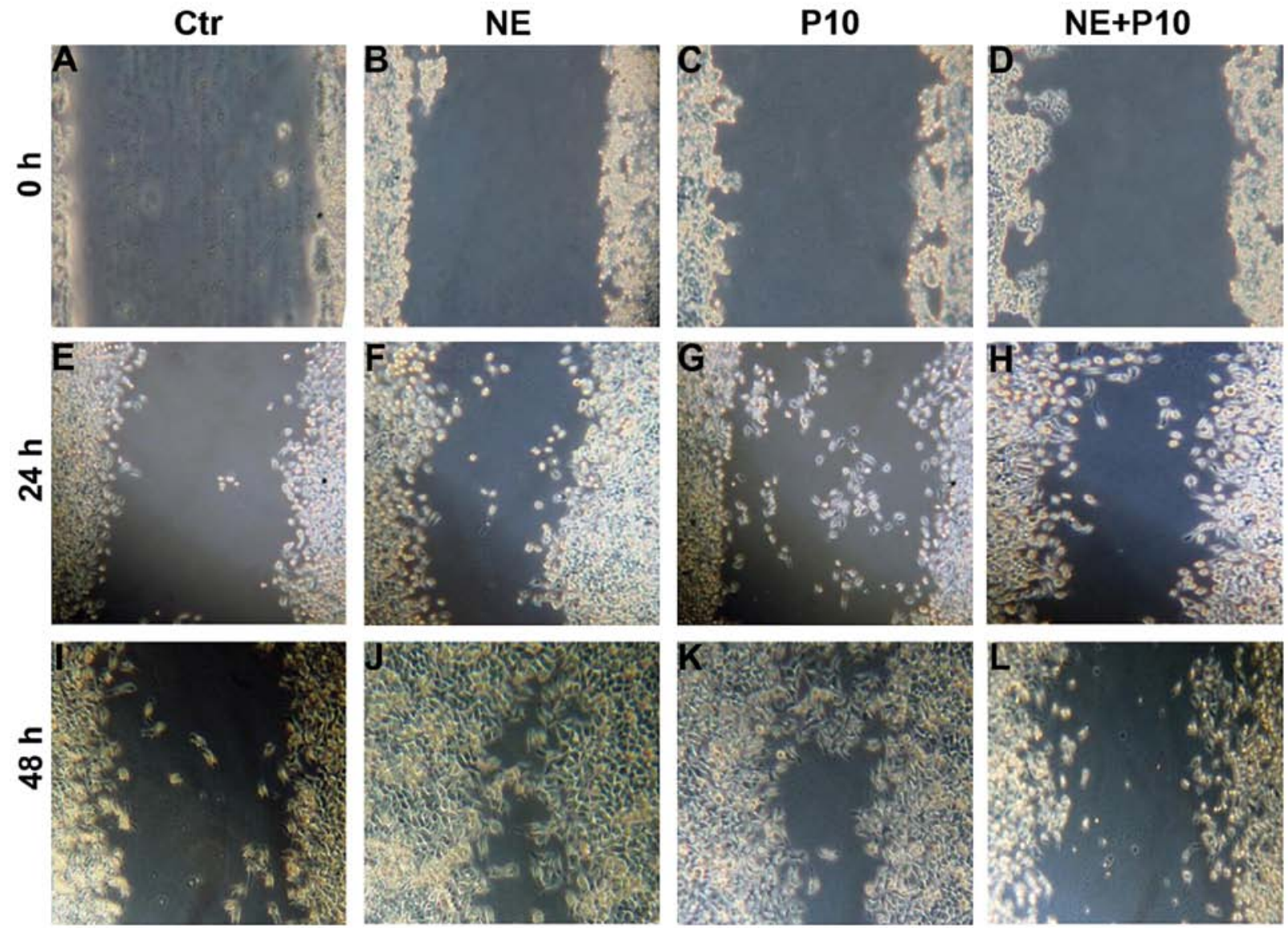

Figure 1. Norepinephrine stimulates proliferation in DU145 cell lines. DU145 cancer cells were incubated in medium containing (A, E and I) medium (Ctr), (B, F and J) $10 \mu \mathrm{m}$ norepinephrine (NE10), (C, G and K), $10 \mu \mathrm{m}$ propranolol (P10), (D, H and L) $10 \mu \mathrm{m}$ propanolol and $10 \mu \mathrm{m}$ propranolol (NE10+P10). Cell migration rates were quantitatively assessed by counting the number of cells in the denuded area at 0,24 , and $48 \mathrm{~h}$ after wound induction. At $48 \mathrm{~h}$ after wound induction, there were clearly more cells in the denuded area of norepinephrine-treated cells than untreated cells or propranolol or combinationtreated cells.

Molecular Devices, Sunnyvale, CA, USA). This reading was divided by the adjusted absorbance reading of untreated cells in control wells to obtain the percentage of cell survival. All experiments were carried out in triplicates.

Histology and immunohistochemistry (IHC). Sections were deparaffinized in xylene for 10 min each and then were rehydrated through graded alcohols. To inhibit endogenous peroxide activity, sections were rinsed in mixture of $100 \%$ methanol and $0.3 \%$ hydrogen peroxide for $40 \mathrm{~min}$. Then, they were put in a microwave oven in a jar filled with $10 \mathrm{mmol} / \mathrm{l}$ sodium citrate buffer ( $\mathrm{pH}$ 6.0) for $10 \mathrm{~min}$. Following this treatment, sections were allowed to cool at room temperature. Sections were incubated with normal goat serum (Zymed, San Diego, CA, USA) at RT for 20 min and then incubated with chicken anti-MMP-2,MMP-9 5-15 $\mu \mathrm{g} / \mathrm{ml}$ (R\&D Systems, Minneapolis, MN, USA) and pan cytokeratin antibody 1:50 (Dako, Italy) at room temperature for $1 \mathrm{~h}$. A negative control was used in all experiments without the primary antibody. After the period of incubation, sections were washed three times with PBS. Then, they were incubated with the linking reagent (biotinlabeled affinity purified antibody; KPL, Gaithersburg, MD, USA) at room temperature for $1 \mathrm{~h}$. After three washes with PBS, the sections were incubated with a complex of avidin DH and biotinylated enzyme (Zymed) at room temperature for $30 \mathrm{~min}$. Then, sections were washed three times with PBS again and incubated with a mixture of an equal volume of $0.02 \%$ hydrogen peroxide and diaminobenzidine tetrahydrochloride (Dako, Italy) for $1 \mathrm{~min}$ in the dark. After chromogenic development, sections were washed in water and counterstained with hematoxylin. The stained slides were investigated independently by two pathologists who had no knowledge of the clinical parameters and outcomes. For microscope analysis of the slides, they each selected five high-powered fields whereby each field contained $>200$ tumor cells, and counted both positive and negative cancer cells. In total, $>1,000$ tumor cells were counted. We calculated the average of 10 readings of positive cells as a percentage of all the cells to determine staining scores. We judged the expression of MMP2 and MMP9 and Pan cytokeratin. The cases were graded as either positive of marker expression (MMP-2, MMP-9, Pan cytokeratin $>30 \%)$ or negative cases $(<30 \%$ positive tumor cells) for the subsequent statistical analyses.

Immunostaining and confocal microscopy. DU145 cells were treated with $10 \mu \mathrm{M}$ norepinephrine (NE10), $10 \mu \mathrm{M}$ propranolol (P10) and N10-P10 combination. After 48 h, DU145 cells were fixed in PBS 4\% paraformaldehyde then permeabilized for 5 min with PBS $1 \%$ Triton. Immunostaining was carried out by incubation with anti-E-cadherin and anti-vimentin antibodies 
1:1,000 followed by revelation using Alexa Fluor 633-conjugated anti-rabbit immunoglobulin (Ig)G antibodies and Alexa Fluor 488-conjugated anti-rabbit IgG antibodies, respectively (Jackson Immunoresearch Laboratories, West Grove, PA, USA) at a dilution of 1:1,000 for $1 \mathrm{~h}$. The cells were analyzed by an LSM-410 Zeiss confocal microscope.

Semiquantitative Rt-PCR analysis. Cells (DU145) grown in monolayers were harvested at early confluence. Total RNA was extracted from cultured cells using TRIzol reagent. The RNA concentration was measured by Biophotometer (Eppendorf) at $260 \mathrm{~nm}$. Then $1 \mu 1$ of the product was subjected to PCR amplification using Mastercycler Personal (Eppendorf, Italy) according to the manufacturer's instructions. Semiquantitative RT-PCR was performed starting with 1cDNA, followed by specific gene product amplification with One-Step RT-PCR kit (Invitrogen, Burlington, ON, Canada). PCR cycling conditions for b2-AR mRNA were $95^{\circ} \mathrm{C}$ for $5 \mathrm{~min}$; then 32 cycles of $94^{\circ} \mathrm{C}$ for $1 \mathrm{~min}, 54^{\circ} \mathrm{C}$ for $1 \mathrm{~min}$, $72^{\circ} \mathrm{C}$ for $1 \mathrm{~min}$; and finally extension at $72^{\circ} \mathrm{C}$ for $7 \mathrm{~min}$. The primer sequences of human b2-AR were designed as follows: forward 5'-ACGCAGCAAAGGGACGAG-3' and reverse 5'-CACACCATCAGAATGATCAC-3'. Experiments were performed three times, for densitometric analysis of each set of data. PCR products were resolved by electrophoresis in $1-2 \%$ agarose gels and visualized by ethidium bromide staining. The densities of the b2-AR bands were divided by those of the GAPDH bands.

Protein extraction and western blot analysis. Cell lysates were prepared by adding ice-cold lysis buffer $[0.5 \%$ Triton X-100, $50 \mathrm{mmol} / \mathrm{l}$ Tris (pH 7.2), $140 \mathrm{mmol} / \mathrm{l} \mathrm{NaCl}, 10 \mathrm{mmol} / \mathrm{l}$ EDTA, $50 \mathrm{mmol} / \mathrm{lNaF}, 1 \mathrm{mmol} / 1 \mathrm{Na}_{3} \mathrm{VO}_{4}$ ] containing the protease inhibitor cocktail Complete Mini (Roche, Mannheim, Germany). Protein samples were mixed with an equal volume of $2 \%$ sodium dodecyl sulfate polyacrylamide gel electrophoresis (SDS-PAGE) sample buffer, boiled for $5 \mathrm{~min}$, and then separated using 10\% SDS-PAGE. After electrophoresis, proteins were transferred to PVDF membranes by semi-dry electrophoretic transfer. The membranes were blocked in $5 \%$ dry milk, rinsed and then incubated with primary antibody of p53 (Sigma) overnight at $4^{\circ} \mathrm{C}$. The primary antibody was removed, membranes were washed four times and followed by HRP-conjugated secondary antibody. Detection was then performed using an enhanced chemiluminescence kit and exposed to X-ray film. Anti $\alpha$-actin was used as loading control.

Statistical analysis. Normally distributed data are presented as mean \pm SEM. Two-way ANOVA and Bonferroni post hoc test, were used to examine the significance of differences among groups (Graph pad Prism 5.0).

\section{Results}

Norepinephrine increases proliferation of DU145 cancer cells. We first determined whether norepinephrine increases the proliferation of human prostate cancer cells DU145 by performing in vitro assays. Proliferation test was performed by wound healing assay on cells treated with norepinephrine at
A

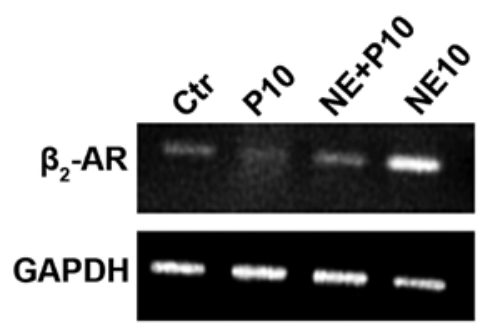

B
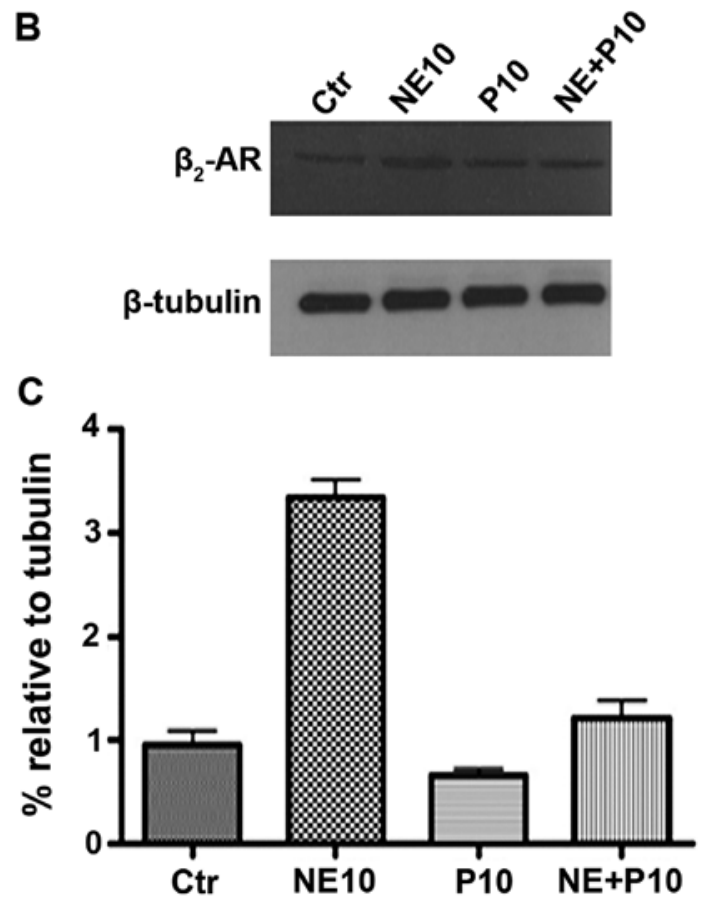

Figure 2. NE influences the expression of $\beta 2-A R$ in DU145 cancer cells RT-PCR analysis shows increased expression of $\beta 2-A R$ in cells treated with $\mathrm{NE}$ respect to control and the other groups. GAPDH $\beta$-actin was used as loading control (B). Western blot analysis shows that $\beta 2$-AR expression is enhanced in DU145 cells treated with NE respect to cells treated with propanol, $\beta$-actin was used as loading control. The intensity of the different bands determined at western blot analysis is represented as columns and normalized for $\beta$-actin loading control. Bars, SEs (C).

$10 \mu \mathrm{M}$ (NE10), propranolol at $10 \mu \mathrm{M}(\mathrm{P} 10)$ and their combination at the same concentration (NE+P10). Our results indicate that norepinephrine (Fig. 1B, F and J) increased the proliferation of DU145 at $48 \mathrm{~h}$ compared to controls (Fig. 1A, E and I), to propranolol (Fig. $1 \mathrm{C}, \mathrm{G}$ and $\mathrm{K}$ ) and the combination (Fig. 1D, H and L). These results were also confirmed by MTT assay (data not shown).

Norepinephrine influencestheexpressionof $\beta 2$-adrenoreceptor in DU145 cell line. Since it has been demonstrated that the expression of $\beta 2$-adrenoreceptor ( $\beta 2$-AR) in DU145 cell line is overexpressed when these cells are treated with norepinephrine, we performed expression studies of $\beta 2$-AR on RNAs and proteins extracted from DU145 cells treated with $10 \mu \mathrm{M}$ norepinephrine (NE10), $10 \mu \mathrm{M}$ propranolol (P10) and their combination (NE+P10). RT-PCR analysis and western blotting results (Fig. 2A and B) showed that norepinephrine causes approximately 3 -fold increase of $\beta 2$-AR protein expression paralleled by enhanced expression of its mRNA. Propanolol almost completely antagonized this effect in DU145 cells. 

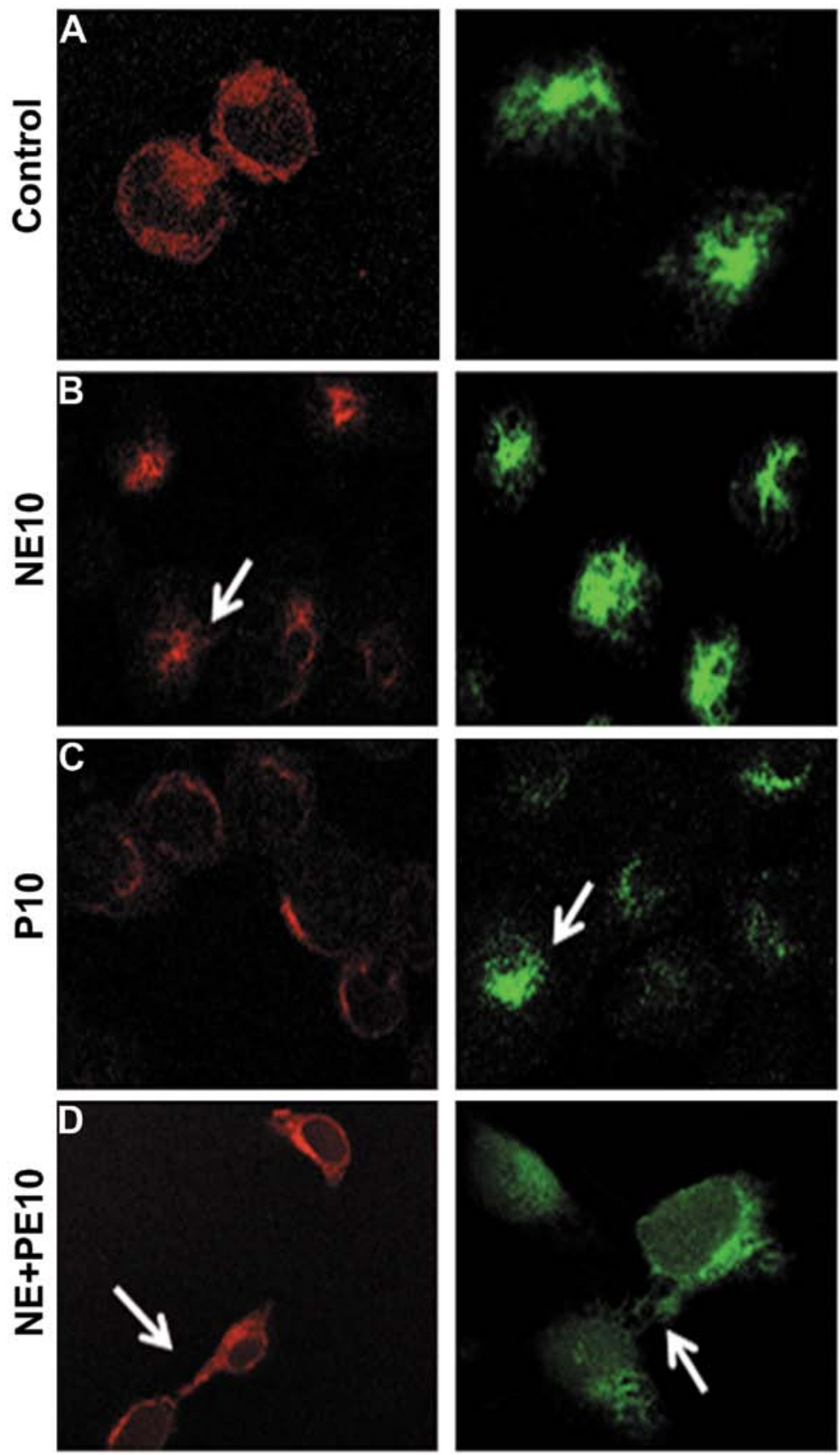

Figure 3. Subcellular localization of E-cadherin (red) and vimentin (green) in DU145 cells. Subcellular localization of E-cadherin (red) and vimentin (green) in DU145 cells without (A) and with $10 \mu \mathrm{M}$ norepinephrine (B), $10 \mu \mathrm{M}$ propranolol (C) and NE10+P10 combination (D). The cells were incubated with antiE-cadherin and anti-vimentin antibodies. Images were obtained by confocal microscopy.

Propranolol antagonizes the effects of norepinephrine on both E-cadherin and vimentin expression and intracellular localization. We investigated the mechanisms of the in vivo acquisition of tumor cell migratory properties induced by norepinephrine treatment and its possible correlation to EMT occurrence. Therefore, we evaluated both cell expression and localization of E-cadherin and vimentin in prostate cancer DU145 cells. Confocal microscopy showed that $10 \mu \mathrm{M}$ norepinephrine (NE10) (Fig. 3B) reduced E-cadherin expression and caused a delocalization of E-cadherin from cell membrane to the cytoplasm. The addition of $10 \mu \mathrm{M}$ propranolol (P10) 30 min before NE10 treatment completely antagonized this effect (Fig. 3D). Moreover, NE10 increased the expression of vimentin and P10 antagonized again this effect together with polar localization of vimentin on the inner side of cell membrane (Fig. 3D). Interestingly, P10 alone had slight effects on E-cadherin expression and localization if compared to untreated cells while inducing a decreased expression and delocalization of vimentin (Fig. 3C). These effects suggest that P10 antagonized the EMT occurrence induced by NE10 that mimics an in vivo stress condition.

The effects of norepinephrine on tumor growth and metastasis formation in a xenograft mouse model of prostate cancer. In order to study the role of norepinephrine on in vivo tumor growth, we generated a mouse model of prostate cancer by 


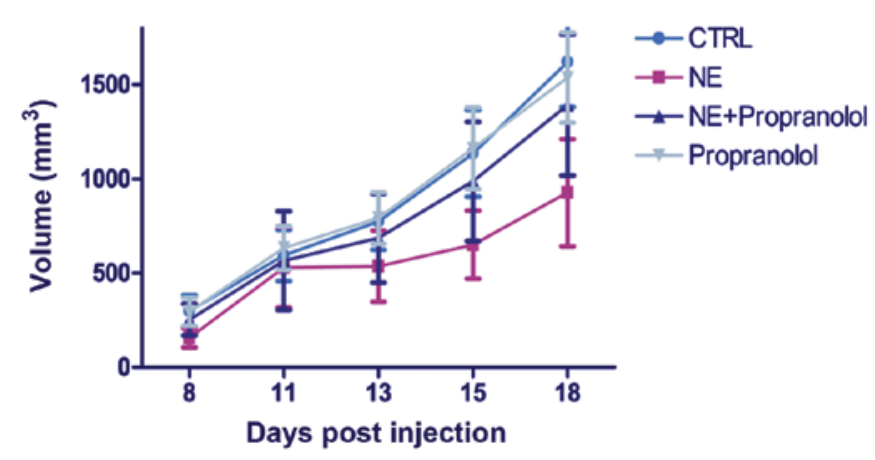

Figure 4. Tumor growth of prostate cancer xenografts in immunocompromised mice. Representative graph of in vivo tumor growth indicates that $\mathrm{NE}$ at concentration of $28 \mathrm{mM}$ does not induce any significant difference of growth of DU145 cell lines compared to control, propranolol and norepinephrine plus propranolol groups $(\mathrm{P}>0.05)$. Bars, SDs.

injection of DU145 cells subcutaneously into the right flank of mice. When tumors reached $\sim 30-60 \mathrm{~mm}^{3}, 2$ weeks following cell injection, the mice were randomized into four groups: a) normal saline (control); b) $28 \mathrm{mM} \mathrm{NE}$; c) $2 \mathrm{mg} / \mathrm{kg}$ propranolol; d) $28 \mathrm{mM} \mathrm{NE}$ and $2 \mathrm{mg} / \mathrm{kg}$ propanol. Tumor volumes were monitored once a week by using a digital caliper. Therapy was continued for 3 weeks. We also monitored the body weight of mice twice a week until the end of treatment. No difference was observed between the body weight of the different animal groups, indicating that treatments of mice with drugs is not associated with toxic effects. Mice were sacrificed at the end of treatment. Differently from that demonstrated by in vitro assays, in vivo experiments showed that norepinephrine is not able to influence the tumor growth of mice $(\mathrm{P}>0.05)$ (Fig. 4). In fact, NE induced an apparent but not significant decrease of tumor volume and this effect was almost completely antagonized again by the treatment with propranolol.

Norepinephrine influences the expression of cytokeratin (CK), $M M P-2$ and MMP-9. In order to show whether norepinephrine in vivo treatment induces the formation of metastasis foci in mice we performed immunostaining for pan-cytokeratin in inguinal lymph nodes in order to find epithelial cells that normally are absent. Our results show a significant increase of the positivity of lymph nodes for cells expressing CK in all the NE-treated animals suggesting a strong increase of metastatic cells and this effect was potently antagonized by propranolol in the combination-treated animals (Fig. 5G, H and I). Moreover, over-
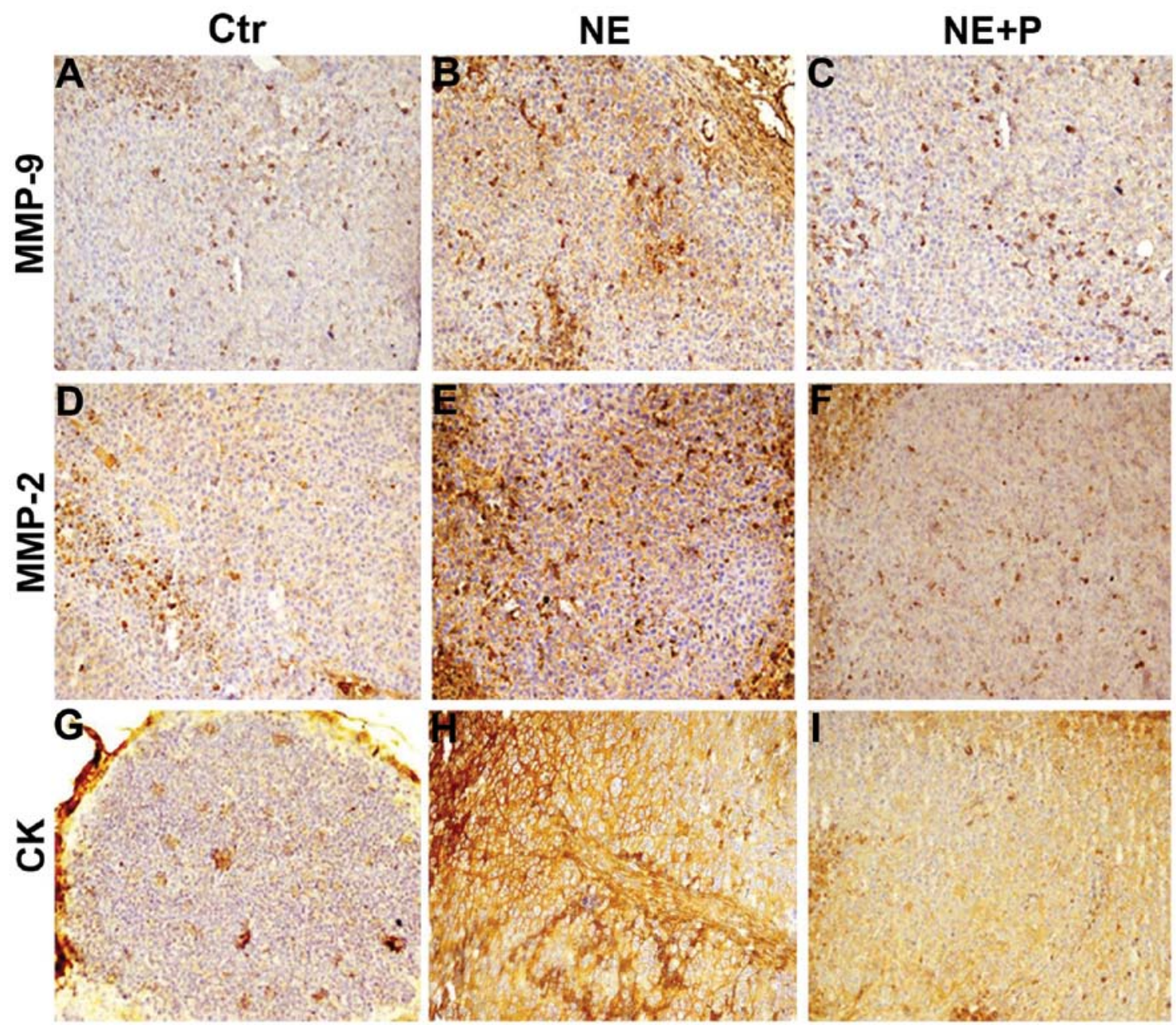

Figure 5. Immunohistochemical analysis of MMP-2, MMP-9 and CK in tumor sections of the mouse model of prostate cancer. MMP-9, MMP-2 and CK expression patterns are enhanced in tumor section of mice treated with NE10 (B, E and H) respect to NE10+P10 (C, F and I) and control groups (A, D and G). Magnification, $\mathrm{x} 10$. 
expression of MMP2 and MMP9 in NE treated tumor samples (Fig. 5B and E) was observed compared to those of controls (Fig. 5A and D) and of mice treated with combination of the two substances (Fig. 5C and F). These data suggest an in vivo EMT effect induced by NE, with consequent increase of the metastatic processes, is not paralleled by tumor growth promotion.

\section{Discussion}

Several preclinical and clinical studies have shown that psychosocial stress has a role in the incidence and progression of cancer. The molecular basis underlying the connection between the neuroendocrine system and malignant tumors is still unclear. In recent years, it has been demonstrated that the immune system plays a role of mediator between these two systems and immunosuppression was supposed to enhance tumor establishment $(11,12)$. Even if this role has been also demonstrated in our previous work on chronic stress and melanoma (13-16), in the present investigation, we dissected the role of $\mathrm{NE}$ in a complex living system represented by athymic mice that lack important parts of the cellular immune system demonstrating its effects also in an immunocompromised model. Moreover, it has been demonstrated that norepinephrine influences the cytotoxicity of natural killer cells (17) that could explain, at least in part, the effects on metastasis formation as we show in this report. In general, immunosuppression by NE or other neurotransmitters might contribute to metastasis formation. Current research has revealed that several neurotransmitters have direct influence on the migratory activity and invasiveness of tumor cells $(7-9,17)$ and does not need the immune system as a mediator. In fact, many studies have demonstrated in vitro that stress-related neurotransmitters are the most potent direct stimulators for the migration of carcinoma cells of various tissue origins. These neurotransmitters are NE, dopamine and substance P (18-22). We showed that the in vitro migratory activity of DU145 cells was increased after the treatment with NE. This leads to an augmented and earlier migration of tumor cells from the primary tumor into inguinal lymph nodes, and consequently to larger metastases formation in mice (23-28). Whether NE leads to organ-specific metastasis to other NE-rich organs must be shown in further experiments with an enhanced study design. Tumor cell migration to lymph nodes occurs rarely in an experimental mouse model of heterotopic cancer because the xenografted tumor mass is generally well encapsulated. Therefore, NE treatment induces an increased migratory effect that is in line with the frequent clinical observation of metastasis development. Lymph nodes and other organs of the immune system, such as bone marrow, thymus and spleen (29) contain noradrenergic and neuropeptidergic nerve fibres and this could induce cell migration into the regional lymph nodes behaving as spreaders (28). Further investigation will be necessary to elucidate the molecular mechanisms underlying the role of NE or other neurotransmitters in metastatic migration towards lymph nodes. We used a model of subcutaneous injection of tumor cells for the investigation of metastasis development in inguinal lymph node because mice initially develop solid primary tumors. The pro-migration effect of $\mathrm{NE}$ in vivo was inhibited by the $\beta$-blocker propranolol that antagonized the prometastatic effect of NE. Furthermore, we showed that propranolol reduced metastases formation in mice compared to controls. This can be related to the blocking of $\beta 2$-AR that is responsible for the effects of norepinephrine endogenously produced by mice. These results open a new scenario for the use of $\beta$-blockers for chemoprevention of metastasis development in patients with diagnosed cancer, because the diagnosis of cancer itself causes stress and especially in prostate cancer patients that are emotionally involved for the impact of the disease on the quality of life (30-36). Moreover, we previously showed that the induction of chronic stress by restraint in mice induced a significant increase of tumor growth and angiogenesis in mice bearing murine melanoma B16F10 paralleled by the activation of $\beta 2-A R$ by neurotransmitters such as E and NE. These effects were completely abolished in eNOS knockout mice (13). In the present study, we demonstrated that stress activates the release of several substances different from catecholamines leading to an increase of migration of tumor cells from primary tumor to lymph nodes without affecting tumor growth (6). Additionally, we demonstrated that norepinephrine increased the expression of CK, MMP-2 and MMP-9 paralleled by EMT effects (E-cadherin loss and vimentin augmentation) $(9-11,16)$, that are indispensable for metastasis formation. The combination of our results delivers good perspectives for the development of non-heart active and $\beta 2$-specific blockers for the inhibition of metastasis development. In conclusion, our results strongly support the concept that the development of metastases is not only genetically determined, but is under the influence of the organism's own signal substances. Further investigation will be necessary in order to dissect the role of neurotransmitters in specific types of cancer and the use of $\beta$-blockers for the chemopreventive inhibition of metastasis development.

\section{Acknowledgements}

The authors would like to specially thank Massimiliano Spinelli and Alessandra Trocino from Istituto Nazionale per lo Studio e la Cura dei Tumori 'Fondazione Giovanni Pascale' - IRCCS, Italy for their kind help in providing informatic assistance. We also thank Michela Falco, Vitale Del Vecchio and Amalia Luce for technical assistance. This work was supported by current research programs of Ministry of Health of Istituto Nazionale per lo Studio e la Cura dei Tumori 'Fondazione Giovanni Pascale', Naples, Italy.

\section{References}

1. Lang K and Bastian P: Neurotransmitter effects on tumor cells and leukocytes. Prog Exp Tumor Res 39: 99-121, 2007.

2. Schuller HM: Neurotransmission and cancer: Implications for prevention and therapy. Anticancer Drugs 19: 655-671, 2008.

3. Liotta LA: An attractive force in metastasis. Nature 410: 24-25, 2001.

4. Entschladen F, Drell TL IV, Lang K, Joseph J and Zaenker KS: Tumour-cell migration, invasion, and metastasis: Navigation by neurotransmitters. Lancet Oncol 5: 254-258, 2004.

5. Entschladen F, Lang K, Drell TL, Joseph J and Zaenker KS: Neurotransmitters are regulators for the migration of tumor cells and leukocytes. Cancer Immunol Immunother 51: 467-482, 2002.

6. Palm D, Lang K, Niggemann B, Drell TL IV, Masur K, Zaenker KS and Entschladen F: The norepinephrine-driven metastasis development of PC-3 human prostate cancer cells in $\mathrm{BALB} / \mathrm{c}$ nude mice is inhibited by beta-blockers. Int J Cancer 118: 2744-2749, 2006. 
7. Drell TL IV, Joseph J, Lang K, Niggemann B, Zaenker KS and Entschladen F: Effects of neurotransmitters on the chemokinesis and chemotaxis of MDA-MB-468 human breast carcinoma cells. Breast Cancer Res Treat 80: 63-70, 2003.

8. Masur K, Niggemann B, Zanker KS and Entschladen F: Norepinephrine-induced migration of SW 480 colon carcinoma cells is inhibited by beta-blockers. Cancer Res 61: 2866-2869, 2001.

9. Lang SH, Hyde C, Reid IN, Hitchcock IS, Hart CA, Bryden AA, Villette JM, Stower MJ and Maitland NJ: Enhanced expression of vimentin in motile prostate cell lines and in poorly differentiated and metastatic prostate carcinoma. Prostate 52: 253-263, 2002.

10. Shan T, Cui X, Li W, Lin W, Li Y, Chen X and Wu T: Novel regulatory program for norepinephrine-induced epithelialmesenchymal transition in gastric adenocarcinoma cell lines. Cancer Sci 105: 847-856, 2014.

11. Shakhar G and Ben-Eliyahu S: In vivo $\beta$-adrenergic stimulation suppresses natural killer activity and compromises resistance to tumor metastasis in rats. J Immunol 160: 3251-3258, 1998.

12. Reiche EM, Nunes SO and Morimoto HK: Stress, depression, the immune system, and cancer. Lancet Oncol 5: 617-625, 2004.

13. Barbieri A, Palma G, Rosati A, Giudice A, Falco A, Petrillo A, Petrillo M, Bimonte S, Di Benedetto M, Esposito G, et al: Role of endothelial nitric oxide synthase (eNOS) in chronic stresspromoted tumour growth. J Cell Mol Med 16: 920-926, 2012.

14. Moreno-Smith M, Lutgendorf SK and Sood AK: Impact of stress on cancer metastasis. Future Oncol 6: 1863-1881, 2010.

15. Feng Z, Liu L, Zhang C, Zheng T, Wang J, Lin M, Zhao Y, Wang $\mathrm{X}$, Levine $\mathrm{AJ}$ and $\mathrm{Hu} \mathrm{W}$ : Chronic restraint stress attenuates p53 function and promotes tumorigenesis. Proc Natl Acad Sci USA 109: 7013-7018, 2012.

16. Moretti S, Massi D, Farini V, Baroni G, Parri M, Innocenti S, Cecchi $\mathrm{R}$ and Chiarugi P: $\beta$-adrenoceptors are upregulated in human melanoma and their activation releases pro-tumorigenic cytokines and metalloproteases in melanoma cell lines. Lab Invest 93: 279-290, 2013.

17. Lang K, Drell TL, Niggemann B, Zänker KS and Entschladen F: Neurotransmitters regulate the migration and cytotoxicity in natural killer cells. Immunol Lett 90: 165-172, 2003.

18. Lang K, Drell TL IV, Lindecke A, Niggemann B, Kaltschmidt C, Zaenker KS and Entschladen F: Induction of a metastatogenic tumor cell type by neurotransmitters and its pharmacological inhibition by established drugs. Int J Cancer 112: 231-238, 2004.

19. Zhang D, Ma Q, Shen S and Hu H: Inhibition of pancreatic cancer cell proliferation by propranolol occurs through apoptosis induction: The study of beta-adrenoceptor antagonist's anticancer effect in pancreatic cancer cell. Pancreas 38: 94-100, 2009.

20. Paredes A, Gálvez A, Leyton V, Aravena G, Fiedler JL, Bustamante D and Lara HE: Stress promotes development of ovarian cysts in rats: The possible role of sympathetic nerve activation. Endocrine 8: 309-315, 1998.
21. Liotta LA and Kohn EC: The microenvironment of the tumourhost interface. Nature 411: 375-379, 2001.

22. Lutgendorf SK, Sood AK and Antoni MH: Host factors and cancer progression: Biobehavioral signaling pathways and interventions. J Clin Oncol 28: 4094-4099, 2010.

23. Vilardi BM, Bravo-Calderón DM, Bernabé DG, Oliveira SH and Oliveira DT: VEGF-C expression in oral cancer by neurotransmitter-induced activation of beta-adrenergic receptors. Tumour Biol 34: 139-143, 2013.

24. Flint MS, Baum A, Episcopo B, Knickelbein KZ, Liegey Dougall AJ, Chambers WH and Jenkins FJ: Chronic exposure to stress hormones promotes transformation and tumorigenicity of 3T3 mouse fibroblasts. Stress 16: 114-121, 2013.

25. Newton PK, Mason J, Bethel K, Bazhenova L, Nieva J, Norton L and Kuhn P: Spreaders and sponges define metastasis in lung cancer: a Markov chain Monte Carlo mathematical model. Cancer Res 73: 2760-2769, 2013.

26. Hara MR, Kovacs JJ, Whalen EJ, Rajagopal S, Strachan RT, Grant W, Towers AJ, Williams B, Lam CM, Xiao K, et al: A stress response pathway regulates DNA damage through $\beta 2$-adrenoreceptors and $\beta$-arrestin-1. Nature 477: 349-353, 2011.

27. Entschladen F, Palm D, Lang K, Drell TL IV and Zaenker KS: Neoneurogenesis: Tumors may initiate their own innervation by the release of neurotrophic factors in analogy to lymphangiogenesis and neoangiogenesis. Med Hypotheses 67: 33-35, 2006.

28. Felten DL: Direct innervation of lymphoid organs: Substrate for neurotransmitter signaling of cells of the immune system. Neuropsychobiology 28: 110-112, 1993.

29. Muller WA: Regulate globally, act locally: adrenergic nerves promote leukocyte recruitment. Immunity 37: 189-191, 2012.

30. Sokołowska P and Nowak JZ: Constitutive activity of beta-adrenergic receptors in C6 glioma cells. Pharmacol Rep 57: 659-663, 2005.

31. Sloan EK, Priceman SJ, Cox BF, Yu S, Pimentel MA, Tangkanangnukul V, Arevalo JM, Morizono K, Karanikolas BD, $\mathrm{Wu} \mathrm{L}$, et al: The sympathetic nervous system induces a metastatic switch in primary breast cancer. Cancer Res 70: 7042-7052, 2010.

32. Armaiz-Pena GN, Cole SW, Lutgendorf SK and Sood AK: Neuroendocrine influences on cancer progression. Brain Behav Immun 30 (Suppl): S19-S25, 2013.

33. Cole SW and Sood AK: Molecular pathways: Beta-adrenergic signaling in cancer. Clin Cancer Res 18: 1201-1206, 2012.

34. Hassan S, Karpova Y, Baiz D, Yancey D, Pullikuth A, Flores A, Register T, Cline JM, D'Agostino R Jr, Danial N, et al: Behavioral stress accelerates prostate cancer development in mice. J Clin Invest 123: 874-886, 2013.

35. Yang EV and Eubank TD: The impact of adrenergic signaling in skin cancer progression: Possible repurposing of $\beta$-blockers for treatment of skin cancer. Cancer Biomark 13: 155-160, 2013.

36. Sood AK and Lutgendorf SK: Stress influences on anoikis (Review). Cancer Prev Res (Phila) 4: 481-485, 2011. 